ВОЛОХ Владимир Александрович - доктор политических наук, профессор Государственного университета управления (109542, Россия, г. Москва, Рязанский пр-кт, 99), илен Совета при Президенте РФ по межнациональным отношениям, илен Общественного совета при МВД России (v.volokh@yandex.ru)

КУРДЮМОВ Николай Викторович - президент союза экспертов и консультантов «Международный альянс “Трудовая миграция” (129090, Россия, г. Москва, пр-кт Мира, 19, стр. 3)

\title{
ПАНДЕМИЯ: ПРОБЛЕМЫ УПРАВЛЕНИЯ МЕЖДУНАРОДНОЙ ТРУДОВОЙ МИГРАЦИЕЙ
}

\begin{abstract}
Аннотация. Авторы отмечают, что Россия является одним из глобальных центров миграционного притяжения и занимает 4-е место по числу принятых мигрантов в мире и 2-е - в Европе. Пандемия коронавируса внесла коррективы в миграционные процессы также и в России. Закрытие границ, прекращение транспортного сообщения между странами, введение карантинных ограничений привело к тому, что граждане, оказавшиеся в этот момент за границей, не смогли вернуться на родину, а также временно не осуществлялся прием документов, оформление и выдача приглашений на въезд в РФ иностранным гражданам, в том числе и трудовым мигрантам.

Оперативный штаб по предупреждению завоза и распространения новой коронавирусной инфекции утвердил разработанный Минтрудом России Алгоритм действий по привлечению в экономику РФ иностранных граждан. Механизмы как Алгоритма, так и организованного набора будут работать при соблюдении трудовыми мигрантами определенных условий, которые предлагают авторы. Делается вывод о необходимости существенного усовершенствования механизмов управления международной миграцией рабочей силы и правового обеспечения реализации государственной миграционной политики.

Ключевые слова: пандемия коронавируса, трудовые ресурсы, алгоритм, организованный набор, межправительственные соглашения, миграционные процессы, миграционная политика, профессиональные стандарты
\end{abstract}

$\mathrm{P}$ оссийская Федерация, наряду с США, Саудовской Аравией и странами Западной Европы, является одним из глобальных центров миграционного притяжения. В настоящее время в мире насчитывается почти 272 млн международных мигрантов, что составляет около 3,5\% всего населения Земли. Россия занимает 4-е место по числу принятых мигрантов в мире и 2-е - в Европе 1.

Анализ, проведенный авторами, показывает, что в 2017-2019 гг. РФ ежегодно посещали 15-16 млн иностранных граждан, из которых 5-6 млн прибывали в страну с целью трудоустройства. Одномоментно на территории страны находились в течение года в среднем до 10-12 млн иностранных граждан, из которых 2-2,5 млн чел. легально осуществляли трудовую деятельность на временной основе.

Значительная часть мигрантов, прежде всего трудовых, въезжают в Россию из государств Центрально-Азиатского региона. Как отмечают С.В. Рязанцев, Е.Е. Письменная, О.Д. Воробьева, Евроазиатский миграционный коридор сформировался на основе устойчивых миграционных потоков между странами Центральной Азии и Российской Федерацией, которые характеризуются масштабными потоками трудовых и учебных мигрантов в пользу России и значительными объемами денежных переводов в пользу посылающих мигрантов стран [Рязанцев, Письменная, Воробьева 2020].

Пандемия коронавируса внесла коррективы в миграционные процессы не

1 Доклад о миграции в мире 2020. Доступ: https://publications.iom.int/system/files/pdf/finalwmr_2020-ru.pdf (проверено 13.07.2021). 
только в других государствах, но и в России. Закрытие границ, прекращение транспортного сообщения между странами, введение карантинных ограничений привело к тому, что граждане, оказавшиеся в этот момент за границей, не смогли вернуться на родину. В связи с прекращением трансграничных поездок населения временно не осуществлялся прием документов, оформление и выдача приглашений на въезд в Российскую Федерацию иностранным гражданам, находящимся за пределами РФ1.

Указом Президента РФ «О временных мерах по урегулированию правового положения иностранных граждан и лиц без гражданства в Российской Федерации в связи с угрозой дальнейшего распространения новой коронавирусной инфекции (COVID-19)» ${ }^{2}$ в РФ до 15 июня 2021 г. было приостановлено течение сроков действия документов и сроков пребывания. Введен мораторий на принятие решений об аннулировании документов иностранным гражданам. Предусмотрены ограничения на осуществление контрольно-надзорной деятельности. В основном не выносились решения о выдворении и депортации.

По мнению российских ученых А.В. Топилина и А.С. Максимовой, «выявлена возрастающая роль внутренней трудовой миграции при сохранении стабильной роли внешней трудовой миграции и снижающихся минимальных показателях вклада постоянной миграции в формирование региональных рынков труда» [Топилин, Максимова 2020].

С учетом дефицита трудовых ресурсов в отдельных отраслях экономики на фоне выхода государств постсоветского пространства из кризиса пандемии и снятия ограничений на въезд в РФ государство предпринимает меры по привлечению иностранных граждан для работы в таких сферах деятельности, как строительство, ЖКХ и сельское хозяйство.

Оперативный штаб по предупреждению завоза и распространения новой коронавирусной инфекции ${ }^{3}$ утвердил разработанный Минтрудом России Алгоритм действий по привлечению в экономику Российской Федерации иностранных граждан ${ }^{4}$ (далее - Алгоритм).

Алгоритм в числе прочего устанавливает возможность для въезда в РФ иностранных работников, привлекаемых российскими работодателями в рамках межправительственных соглашений РФ об организованном наборе иностранных граждан. В настоящее время действуют два таких соглашения об организо-

1 Распоряжение Правительства РФ от 18.03.2020 № 635-р «О временном ограничении въезда в Российскую Федерацию иностранных граждан и лиц без гражданства, в том числе прибывающих с территории Республики Белоруссия, а также граждан Республики Белоруссия». Доступ: https://docs.cntd.ru/document/564453451 (проверено 12.07.2021).

2 Указ Президента РФ от 18.04.2020 № 274 «О временных мерах по урегулированию правового положения иностранных граждан и лиц без гражданства в Российской Федерации в связи с угрозой дальнейшего распространения новой коронавирусной инфекции (COVID19)» в ред. Указа Президента РФ от 15.12.2020 № 791 «О продлении действия временных мер по урегулированию правового положения иностранных граждан и лиц без гражданства в Российской Федерации в связи с угрозой дальнейшего распространения новой коронавирусной инфекции (COVID-19)». Доступ: http://www.consultant.ru/document/cons_doc_ LAW_350638/(проверено 12.07.2021).

3 Михаил Мишустин утвердил состав оперативного штаба по предупреждению завоза и распространения новой коронавирусной инфекции на территории России. Доступ: http:// government.ru/news/38865/ (проверено 12.07.2021).

${ }^{4}$ Информация Правительства РФ от 14.01.2021 г. «Алгоритм действий по привлечению в экономику Российской Федерации иностранных граждан» (прил. N 3 к протоколу заседания Оперативного штаба по предупреждению завоза и распространения новой коронавирусной инфекции на территории Российской Федерации от 14 января 2021 г. N 1кв). Доступ: https://www.garant.ru/products/ipo/prime/doc/400267019/ (проверено 12.07.2021). 
ванном наборе - это соглашение с Республикой Узбекистан от 5 апреля 2017 г. ${ }^{1}$ и соглашение с Республикой Таджикистан от 19 апреля 2019 г. $^{2}$

Механизмы Алгоритма и организованного набора направлены на формирование условий, когда работодатели отбирают в государствах выезда трудовых мигрантов определенных профессий и квалификации. Организованная трудовая миграция позволяет обеспечить российским работодателям доступ к востребованным трудовым ресурсам, привлечь в оговоренные сроки нужное число иностранных работников необходимой квалификации.

Практика показывает, что механизмы как Алгоритма, так и организованного набора будут работать при соблюдении трудовыми мигрантами следующих условий:

- соответствия профессионально-квалификационным требованиям заявки работодателя и тем характеристикам, которые были выявлены и зафиксированы направляющей стороной в ходе предвыездной подготовки в государстве выезда;

- осуществления трудовой деятельности по приезде в РФ именно у работодателя-заказчика и в регионе, где работодатель согласовал потребности в иностранной рабочей силе;

- выполнения трудовой деятельности по профессии, которая указана в заявке работодателя и была подтверждена в процессе отбора и предвыездной подготовКИ.

Если эти условия не выполняются, и трудящиеся мигранты осуществляют трудовую деятельность не в тех организациях, где они востребованы, или трудятся по профессиям, не соответствующим заявке работодателя, оргнабор превращается в механизм упрощенного въезда иностранцев в РФ с частичной оплатой расходов за счет работодателей и в ряде случаев - с нелегальным их участием в дальнейшей трудовой деятельности.

К сожалению, на практике значительная часть трудовых мигрантов, которые были отобраны в процессе оргнабора, после приезда в российские регионы, в нарушение условий договора, самостоятельно находят новую работу, а нередко и переезжают в другие регионы. Ключевую роль в этих так называемых процессах перераспределения иностранных трудовых ресурсов играет теневой рынок труда через посредников, которые предлагают участникам оргнабора «более выгодную работу».

Нарушение условий договора (самовольная смена места работы иностранными работниками, отобранны и привлеченны в рамках оргнабора) имеет многочисленные негативные последствия для инициировавшего их въезд бизнеса:

- работодатель-заказчик не получает необходимых работников и, потеряв временные и материальные ресурсы, теряет доверие к организованным формам трудовой миграции;

- иностранный работник, чаще всего нелегально, переходит на несогласо-

1 Соглашение между Правительством Российской Федерации и Правительством Республики Узбекистан об организованном наборе и привлечении граждан Республики Узбекистан для осуществления временной трудовой деятельности на территории Российской Федерации от 5 апреля 2017 г. (ратифицировано федеральным законом от 05.12.2017 № 366-Ф3, вступило в силу 21 декабря 2017 года). Доступ: https://docs.cntd.ru/ document/542614408 (проверено 12.07.2021).

2 Соглашение между Правительством Российской Федерации и Правительством Республики Таджикистан об организованном наборе граждан Республики Таджикистан для осуществления временной трудовой деятельности на территории Российской Федерации от 17 апреля 2019 г. (ратифицировано федеральным законом от 27.12.2019 № 466-Ф3, вступило в силу 22.01.2020). Доступ: http://publication.pravo.gov.ru/Document/ View/0001202002260045 (проверено 12.07.2021). 
ванное рабочее место и конкурирует с российским соискателем работы, что приводит к негативному восприятию трудовой миграции в российском обществе;

- нередко работа, на которую самовольно и нелегально переходит иностранный работник, носит неоформленный характер, и трудовой мигрант пополняет теневой рынок труда, теряет урегулированный статус пребывания со всеми вытекающими отсюда последствиями.

Все эти процессы создают инфраструктуру теневого рынка труда и усиливают влияние нелегальных посредников, связанных с ними работодателей и недобросовестных представителей профильных силовых структур.

Указанные негативные последствия такого «организованного» набора нередко приводят к обсуждению вопроса, а нужно ли вообще заниматься оргнабором, если его результаты непредсказуемы. Однако подавляющая часть экспертного сообщества отмечает, что текущее состояние оргнабора - результат отсутствия внимания к нему как со стороны профильных государственных структур, так и крупных бизнес-формирований, прежде всего ведущих объединений работодателей.

Организованный набор - это регулируемый процесс привлечения востребованных иностранных трудовых ресурсов с учетом количественных и качественных их характеристик (профессия, квалификация, готовность к адаптации и т.д.) и переноса в государства выезда большей части работы по подготовке и контролю соответствия трудящихся мигрантов потребностям российского рынка труда. На наш взгляд, альтернативы организованному/целевому набору нет, и необходимо создать правовые, организационные и иные условия, чтобы эти процессы заработали эффективно.

Рассмотрим, какие меры необходимо предпринять, чтобы минимизировать риски заинтересованных участников организованного набора.

Прежде всего, необходимо исключить из процессов организованного набора трудовых мигрантов тех его участников, которые еще в процессе отбора и предвыездной подготовки рассматривали оргнабор только как путь переезда в Россию, а не трудовой деятельности у конкретного работодателя. Также это касается и организаций - недобросовестных посредников, которые привлекают иностранных работников только для того, чтобы потом нелегально передать их, в нарушение условий договора, другим работодателям.

Исключив заведомо недобросовестных участников оргнабора, важно минимизировать риски проблемных ситуаций в процессах оргнабора. Эти проблемы связаны как с работодателями, так и с работниками.

Проблемные ситуации, которые связаны с нарушениями условий оргнабора со стороны работодателей, относительно редки, что можно объяснить процедурами проверки работодателей и возможностью их наказания. Чаще всего эти вопросы возникают в связи с отсутствием знаний миграционного законодательства, неготовностью профильных специалистов компании в должной мере контролировать процесс оргнабора. Подготовка работодателей к участию в оргнаборе и сопровождение координаторами оргнабора с российской стороны процесса участия работодателей в реализации механизмов организованного набора - отдельное направление работы.

Что касается основных проблемных ситуаций, связанных с трудовыми мигрантами, то их можно разделить на две составляющие:

- самовольный уход работников от работодателя - заказчика оргнабора в первые месяцы после приезда в поисках потенциально лучших условий работы в нарушение условий договора;

- несоответствие кандидатов на участие в оргнаборе требованиям работода- 
теля - формальное проведение процедур отбора и предвыездной подготовки в государстве выезда.

Исключение таких проблемных ситуаций отвечает интересам как работодателя, так и, прежде всего, самого работника. Если трудовой мигрант не соответствует требованиям работодателя или самовольно, в нарушение договора, «уходит от него», он, как правило, оказывается клиентом посредников теневого рынка труда и в результате не получает тот заработок, который ему обещали посредники, а сама работа осуществляется нелегально, без соответствующего оформления. Многие иностранные работники, самовольно покинув работодателя-заказчика, позднее хотели бы вернуться к нему, но их неурегулированный статус и другие причины не позволяют это сделать.

Как правовыми путями закрепить иностранных работников - участников оргнабора за работодателем-заказчиком?

Минимизация рисков участников оргнабора на этапе работы отправляющей стороны по отбору и предвыездной подготовке кандидатов является одним из наиболее важных звеньев оргнабора. Процессы отбора и предвыездной подготовки кандидатов в соответствии с запросами работодателей нуждаются в детальной регламентации всех этапов с учетом включения работодателя в процесс контроля за ними. Работодатель-заказчик или его уполномоченный представитель должны быть уверены, что кандидаты понимают все требования к ним, условия трудовой деятельности и быта в соответствии с заявкой работодателя и готовы нести ответственность за их нарушение.

Профессионально-квалификационные требования к кандидатам должны быть также формализованы в виде соответствующих процедур и тестов. Важно, чтобы работа на площадках предвыездной подготовки по тестированию на соответствие профессиональных характеристик кандидатов, профессиональное обучение и дальнейшая профессиональная аттестация были основаны на требованиях российских профессиональных стандартов. К этой работе важно привлечь отраслевые советы по профессиональным квалификациям национальной системы квалификаций РФ.

Необходимо так организовать работу по отбору и предвыездной подготовке, чтобы направляющая сторона несла реальную ответственность за несоответствие кандидатов тем характеристикам и показателям, которые зафиксированы в заявках работодателей и указаны направляющей стороной по итогам работы с кандидатами.

Масштаб потребности российского бизнеса в трудовых ресурсах требует принятия мер, направленных на получение максимальной отдачи от существующих институтов организованного привлечения трудовых ресурсов. В связи с этим жизненно востребовано создание структуры, регулирующей со стороны бизнес-сообщества механизм организованного набора и выполняющей функцию консультационной, правовой и организационной поддержки и сопровождения российских работодателей в процессе их работы с партнерами в государствах выезда трудовых мигрантов.

Такой структурой-координатором от бизнес-сообщества могли бы стать объединения работодателей, наиболее тесно взаимодействующие как с крупным, так и с малым бизнесом и хорошо понимающие их проблемы в сфере привлечения востребованных трудовых ресурсов.

Торгово-промышленная палата РФ с учетом наличия разветвленной сети территориальных торгово-промышленных палат в регионах страны могла бы выступать в роли такого координатора организованного набора со стороны российского бизнеса в направлении:

- консультационной, правовой, организационной поддержки и сопровожде- 
ния работодателей и операторов организованного набора в процессе их работы с зарубежными партнерами, что снизит издержки российского бизнеса и позволит вовлечь в механизм организованного набора малый и средний бизнес;

- проведения мониторинга процессов оргнабора и подготовки предложений по его развитию;

- разработки и внедрения инструментов урегулирования конфликтных ситуаций, возникающих между участниками оргнабора;

- подготовки рекомендаций в целях эффективного и согласованного с работодателем-заказчиком функционирования площадок предвыездной, доиммиграционной подготовки и площадок профессиональной подготовки и аттестации трудовых мигрантов за рубежом;

- разработки системных квалификационных требований к организаторам и операторам организованного набора, поэтапной реализации программ их обучения и независимой аттестации на соответствие необходимым требованиям к квалификации;

- информирования и консультирования российского бизнеса по вопросам требований к участникам организованного набора, в т.ч. в части потенциальной возможности привлекать иностранный персонал с учетом установленных национальным законодательством ограничений.

Однако, даже если будет отработан механизм сопровождения процессов оргнабора с учетом минимизации рисков проблемных ситуаций, останется ключевая проблема эффективного развития организованного набора: отсутствие правовых стимулов для участников этих процессов.

Участники оргнабора должны иметь реальные правовые и организационные преференции по сравнению с теми работодателями и трудовыми мигрантами, которые по разным причинам не принимают участие в оргнаборе. Такие преференции необходимо разработать профильным ФОИВам РФ совместно с экспертным сообществом. Среди предложений, которые можно было бы рассмотреть, фигурируют сокращение сроков оформления разрешительных документов для участников оргнабора, гарантированная возможность уменьшения работодателем суммы исчисленного и удержанного налога на сумму фиксированных авансовых платежей по НДФЛ, уплачиваемых «за пользование патентом», и др. Обсуждается и возможность освободить иностранных работников участников оргнабора от комплексного экзамена по русскому языку. Однако, на наш взгляд, реализация такого предложения только ослабит процессы предвыездной подготовки, через которые должны пройти кандидаты для участия в оргнаборе.

В связи с этим перед Министерством внутренних дел РФ в части управления миграционными процессами стоят сложные задачи, прежде всего связанные с тем, что на ведомство возложены новые функции, не в полной мере свойственные «силовому ведомству», - адаптация и интеграция мигрантов, реализация государственной программы содействия добровольному переселению соотечественников, проживающих за рубежом, регулирование процессов внешней трудовой и внутренней миграций, а также ряд гуманитарных функций, например работа с беженцами и вынужденными переселенцами, - иными словами, функции, связанные с социально-экономическим и демографическим развитием страны, а также участие в реализации национальной, внешней и внутренней политики России в части миграции населения.

В перспективе, на наш взгляд, целесообразно создать новый федеральный орган исполнительной власти, который будет разрабатывать предложения для высшего политического руководства страны в части формирования нацио- 
нальной и миграционной политики и комплексно управлять всеми миграционными процессами [Волох 2017].

Рассматриваемые вопросы особенно актуальны в настоящее время, когда наше общество, экономика страны находятся на этапе постепенного выхода из комплекса ограничительных мер, связанных с угрозой распространения коронавирусной инфекции.

Эпидемия коронавируса показала, насколько механизмы миграционной политики готовы к таким экстренным ситуациям. И сейчас с уверенностью нельзя сказать, случится ли это еще раз в ближайшее время, не мутирует ли новый штамм коронавируса и не придется ли вводить новые ограничительные меры. В любом случае, политической науке на сегодняшний день необходимо совершенствовать механизмы управления международной миграцией рабочей силы и правового обеспечения реализации государственной миграционной политики.

\section{Список литературы}

Волох В.А. 2017. Проблемы управления миграционными процессами в современной России. - Управление. № 2(16). С. 35-42.

Рязанцев С.В., Письменная Е.Е., Воробьева О.Д. 2020. Евроазиатский миграционный коридор: теоретические аспекты, оценки масштабов и ключевые характеристики. - Научное обозрение. Сер. 1. Экономика и право. № 3-4. С. 5-18.

Топилин А.В., Максимова А.С. 2020. Роль миграции в формировании региональных рынков труда в условиях второй волны депопуляции в современной России. - Вопросы статистики. Т. 27. № 6. С. 26-36.

VOLOKH Vladimir Aleksandrovich, Dr.Sci. (Pol.Sci.), Professor of the State University of Management (99 Ryazansky Ave, Moscow, Russia, 109542); Member of the Presidential Council on Interethnic Relations, Member of the Public Council under the Ministry of Internal Affairs of Russia (v.volokh@yandex.ru)

KURDYUMOV Nikolay Viktorovich, President of the Union of Experts and Consultants «International Alliance «Labor Migration» (bld. 3, 19 Mira Ave, Moscow, Russia, 129090)

\section{THE PANDEMIC: PROBLEMS OF MANAGING INTERNATIONAL LABOR MIGRATION}

Abstract. The authors note that Russia is one of the global centers of migration attraction and ranks the $4^{\text {th }}$ in the number of accepted migrants in the world and the $2^{\text {nd }}$ in Europe. The coronavirus pandemic adjusts migration processes in Russia also. The closure of borders, the termination of transport links between the countries, the introduction of quarantine restrictions led to the fact that citizens who were abroad at that moment could not return to their homeland. The reception of documents, registration and issuance of invitations to enter the Russian Federation to foreign citizens, including labor migrants were not available.

The Operational headquarters for the prevention of the import and spread of a new coronavirus infection has approved the Algorithm of Actions developed by the Ministry of Labor of the Russian Federation to attract foreign citizens to the economy of the Russian Federation. The mechanisms of both the algorithm and the organized recruitment will work if labor migrants comply with certain conditions that the authors propose. They concluded that today it is necessary to improve the mechanisms for managing international labor migration and legal support for the implementation of the state migration policy. Keywords: coronavirus pandemic, labor resources, Algorithm of Actions, organized recruitment, intergovernmental agreements, migration processes, migration policy, professional standards 